\title{
Cost-Effectiveness of Positron Emission Tomography in Recurrent Colorectal Cancer in Canada
}

\author{
Jeffrey Scott Sloka, M.D., Ph.D. $\dagger^{* *}$, Peter Dorroch Hollett, M.D. ${ }^{\S}$, K. \\ Maria Mathews, Ph.D. ${ }^{¥}$
}

\begin{abstract}
BACKGROUND: Several studies over the past decade have demonstrated that 2-fluoro-2-D-
[ ${ }^{18}$ F] fluorodeoxyglucose (FDG) positron emission tomography (PET) is more accurate than computed tomography (CT) for the staging of recurrent colorectal carcinoma. This study uses quantitative decision tree modeling and sensitivity analysis to assess the cost-effectiveness of a PET-based management strategy for staging recurrent colorectal carcinoma in Canada. Both management costs and life expectancy are determined. METHODS: Two patient management strategies were compared - one using CT alone and one using both CT and PET. A survey of recent literature was used to construct a meta-analyses of available studies for the accuracy of PET in staging recurrent colorectal carcinoma. Life expectancies were determined from recent Canadian statistics, and expected life expectancies with disease were calculated from published survival rates. Management costs were determined from: estimates of the installation cost of PET facilities in Canada; management costs from our institutions; and recently published Canadian cost estimates of various procedures. RESULTS: A cost savings of \$1,758 per person is expected for a PET and CT strategy, along with a slight increase in life expectancy (3.8 days), when compared with a CT alone strategy. This cost savings stemmed from avoided surgeries and remained in favour of the PET strategy when subjected to a rigorous sensitivity analysis.
\end{abstract}

\section{INTRODUCTION}

Colorectal cancer is a significant cause of morbidity and mortality in the Canadian population. In the year 2001, there were 17,000 new cases of colorectal cancer in Canada, and 6,500 people died from the disease (1). Colorectal cancer is also an expensive disease to diagnose and treat. Diagnostic tools such as CT imaging and colonoscopy are used to guide expensive treatment options such as chemotherapy and surgery. The accuracy of testing is essential for cost-effective

\footnotetext{
* To whom correspondence should be addressed: Jeffrey Scott Sloka, $\mathrm{MD}, \mathrm{PhD}$, Faculty of Medicine, Memorial University of Newfoundland 108 Moss Heather Dr., St. John's, Newfoundland, A1B 4S1 e-mail: p97jss@mun.ca

$\dagger$ Faculty of Medicine, Memorial University of Newfoundland

$\S$ Chief - Division of Nuclear Medicine, Department of Medical Imaging, Health Care Corporation of St. John's, St. John's, Newfoundland

$¥$ Assistant Professor Health Policy/Heath Care Delivery Division of Community Health, Memorial University of Newfoundland
}

decision making. Inaccuracies result in additional and inappropriate procedures (e.g. surgeries, colonoscopies) that both put the patient at an increased risk of procedure morbidity and mortality, and extra costs are incurred by the third party payer. The addition of a new, more accurate diagnostic test to the decision process benefits both the patient and the third party payer by reducing the number of inappropriate procedures.

Of the people who initially present with colorectal cancer and are resected for cure, $25-40 \%$ have disease recurrence, a proportion of whom are potentially curable by a second resection (Figure 1). Patients who present for detection and staging of recurrent colorectal cancer have a prevalence of recurrent disease of approximately $85 \%$ (2)(Table 1). The cost effective surveillance, diagnosis, and therapy for the recurrence of colorectal cancer depends on the accurate determination of who is appropriate for a second 


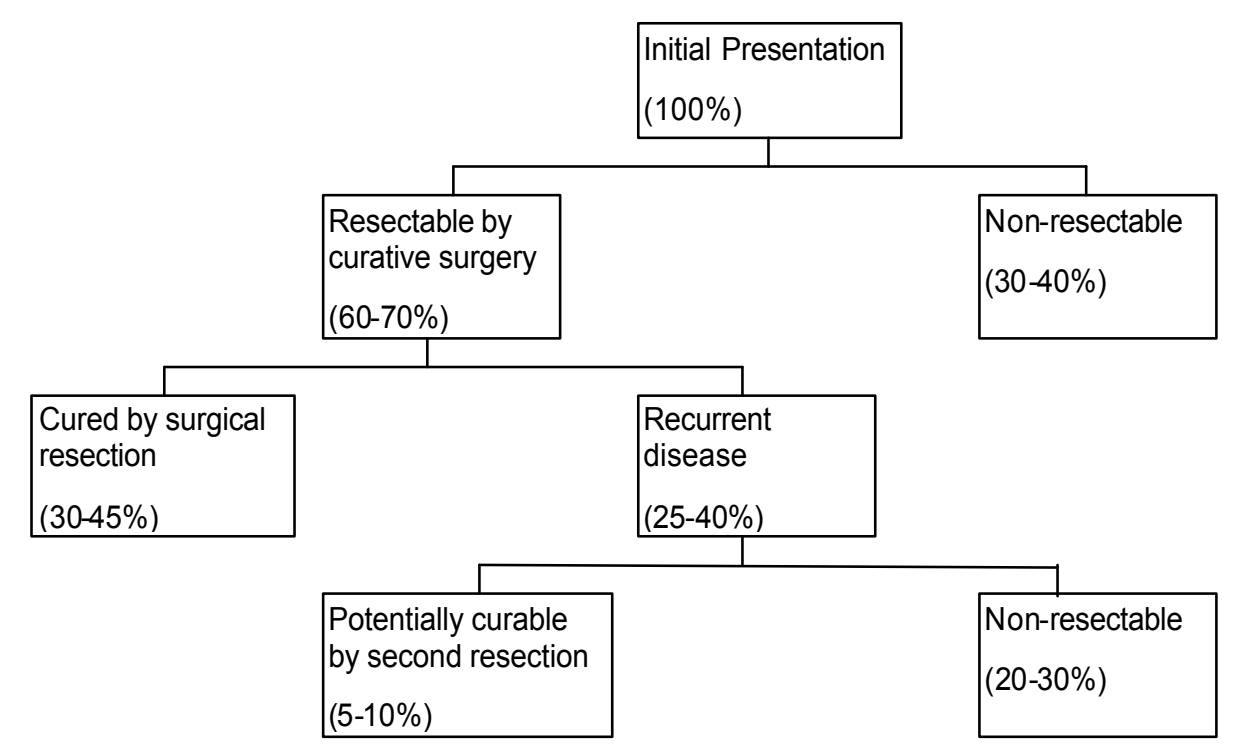

Figure 1. Epidemiological natural history of recurrent colorectal cancer. (Percents represent a proportion of those patients that initially present)(11). Sixty to seventy percent of new cases present with primary stage II or III disease, most of whom are potential candidates for curative surgical resection(11). After surgical resection, metastatic or locally invasive disease, primarily to the liver or lung, recurs in 35-40\% of patients $(25-40 \%$ of total presentations)(11;12), and approximately $25 \%$ of these recurrences are potentially curable. Only $29-46 \%$ of curative resection candidates are truly resectable at the time of surgery due to the underestimation of the extent of disease(12-20)

surgical resection. Preoperatively, a computed tomography (CT) study is ordered by the surgeon to aid in localization of recurrence.

Positron Emission Tomography (PET) utilizing [ ${ }^{18}$ F]2-fluoro-2-deoxy-D-glucose (FDG) has been evaluated in several clinical studies for use in staging recurrent colorectal cancer and guiding treatment (2-8). PET using FDG is a noninvasive imaging modality that provides information useful for tumor imaging $(9,10)$. Increased glucose utilization by malignant cells results in increased FDG uptake, which is used to localize metastatic sites. PET examines the entire body and can therefore identify sites of distant metastases in the pelvis, liver and lung. Studies have shown that PET may be more sensitive and specific than CT in detecting localized and metastatic recurrence of disease and therefore may be more accurate for directing surgical management (2-8).

The aim of this study is to compare two diagnostic strategies for recurrent colorectal cancer, one employing CT only and one employing PET and CT. The study will compare the marginal cost effectiveness of the addition of PET for the preoperative staging of recurrent colorectal cancer in Canada and will also compare the number of unnecessary surgeries performed between the two strategies. (Cost effectiveness analysis compares both economic costs/benefits and survival outcomes of proposed management strategies and expresses the results as a ratio of costs spent or saved to an outcome, e.g. number of life years saved (21)). The effects of the additional diagnostic tests are also compared in terms of the difference in life expectancies to determine any detriment to the patient. The viewpoint of the analysis is the hospital.

The cost effectiveness of using PET for the staging of recurrent colorectal cancer has been demonstrated by others in certain economic environments $(22,23)$. However, the cost effectiveness of PET for recurrent colorectal cancer has not been studied for centers in Canada.

\section{METHODS \\ Model structure}

Decision models of established protocols from both the literature $(5,24)$ and from current local practice were structured with two outcomes: cost and life expectancy (Figure 2), so that comparison of outcomes (total expected costs, expected life expectancy, and total number of surgeries) could be made. To construct the decision tree, the sensitivity and specificity values of each diagnostic test were identified. Mortality rates of each procedure were also determined as reported in the literature. The time horizon of the study was from the initial diagnostic studies to the final treatment modalities of the first disease recurrence.

The first decision tree uses CT to stage the patient's disease, while the second decision tree uses both PET and CT to stage the patient's disease. All results from the image modality (conservatively) have a colonoscopy performed with subsequent biopsy if positive. If negative, the disease is confirmed using biopsy or diagnostic laparotomy. All patients receive a 
CT study in the PET strategy to provide the surgeon with anatomical information necessary for surgery. Every patient with a positive PET result, regardless of the CT result, is sent to biopsy for confirmation of disease (conservative treatment), thus ensuring that patients who are falsely positive of metastases receive the benefit of curative surgery. In the decision trees, a "+ve" in a particular test indicates that the patient has tested positive for metastatic disease. Further tests may be required to confirm this, at which time the patient may be a candidate for other therapies such as chemotherapy.

\section{Population}

In terms of life expectancy calculations, the representative population chosen for this study is a 65 year old person (an average age of presenting patients from some recent studies (25-29)), presenting with suspected recurrent colorectal cancer (having a mean survival of 16 months (30)), a proportion of whom are not candidates for resection due to disease extent. We used a theoretical sample of 1000 patients to estimate the number of procedures for each strategy.

\section{Probabilities}

Meta-analysis is the technique of combining the results of several studies to strengthen conclusions about individual studies when taken as a whole. Following guidelines outlined in the literature $(31,32)$, a search was performed using: the MEDLINE keywords "PET, CT, and recurrent colorectal cancer"; published abstracts; and references noted in the above studies.

Table 1. Parameters used in the decision model. The derivation of all parameters appears throughout the methods section. The disease prevalence is the prevalence of recurrent colorectal cancer in the population of patients presenting for diagnosis of recurrence.

\begin{tabular}{llll}
\hline Population & \multicolumn{3}{l}{ Biopsy } \\
\hline Disease prevalence & $\mathbf{8 5 \%}$ & $\begin{array}{l}\text { Cost } \\
\text { Mortality }\end{array}$ & $\$ 118$ \\
& & $\begin{array}{l}\text { Sensitivity } \\
\text { CT }\end{array}$ & $100 \%$ \\
Cost & $\$ 462$ & Specificity & $100 \%$ \\
Mortality & $0.0025 \%$ & & \\
Sensitivity & $76.2 \%$ & Surgical Resection & \\
Specificity & $69.4 \%$ & Cost & $\$ 16479$ \\
& & Mortality & $6.5 \%$ \\
PET & & & \\
Cost & $\$ 1029$ & Life expectancy & $17.4 \mathrm{yrs}$ \\
Mortality & $0 \%$ & Local population \\
Sensitivity & $93.3 \%$ & Patients with stage IV & $1.1 \mathrm{yrs}$ \\
Specificity & $92.7 \%$ & Patients after curative & $2.6 \mathrm{yrs}$ \\
& & surgery & \\
Colonoscopy & & & \\
Cost & $\$ 168$ & Chemotherapy & \\
Mortality & $0.005 \%$ & Cost & see text \\
Sensitivity & $93 \%$ & & \\
Specificity & $95 \%$ & & \\
\hline
\end{tabular}

Selected studies included both retrospective and prospective studies (2-8). Studies that did not publish the numbers used to derive the sensitivity and specificity were not included in the meta-analysis because combined sensitivities and specificities could not then be calculated. Only studies that confirmed the diagnosis with biopsy were included, and because this study determines outcomes based on the patient, any study that published sensitivities and specificities based strictly on the number of identified lesions was not included (33). No tests of homogeneity were used, however Figure 3 indicates the study results visually.

The aggregate average of eight studies was used to calculate the model sensitivities and specificities (2-7, 34). These studies did not have an equal average age of patients, and some did not blind the results between the PET and CT studies. Since a stricter set of inclusion criteria results in smaller numbers of patients in the meta analysis, most studies were included in determining the aggregate average with the knowledge that some variability across diagnostic usage and patient population would exist. It was noted, however, that all included studies showed PET to be more sensitive and specific within each study.

\section{Alteration of surgical management}

The use of FDG-PET has been reported to alter the management of patients prior to surgery given the additional accuracy PET provides over CT staging (2,48, 35-37). Alteration of management may include: the detection of unknown liver metastases which may augment surgical management; the detection of extensive metastases which may exclude the possibility of surgery and direct the management towards chemotherapy and/or palliative care; or the addition of surgical management if recurrent cancer is confirmed

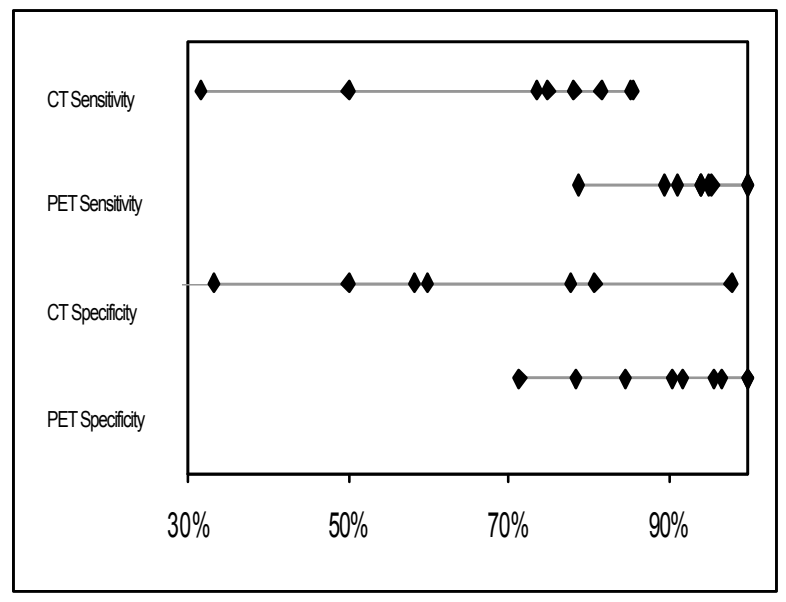

Figure 3. CT and PET sensitivities and specificities for 8 studies used in the meta analysis plotted to demonstrate clustering 

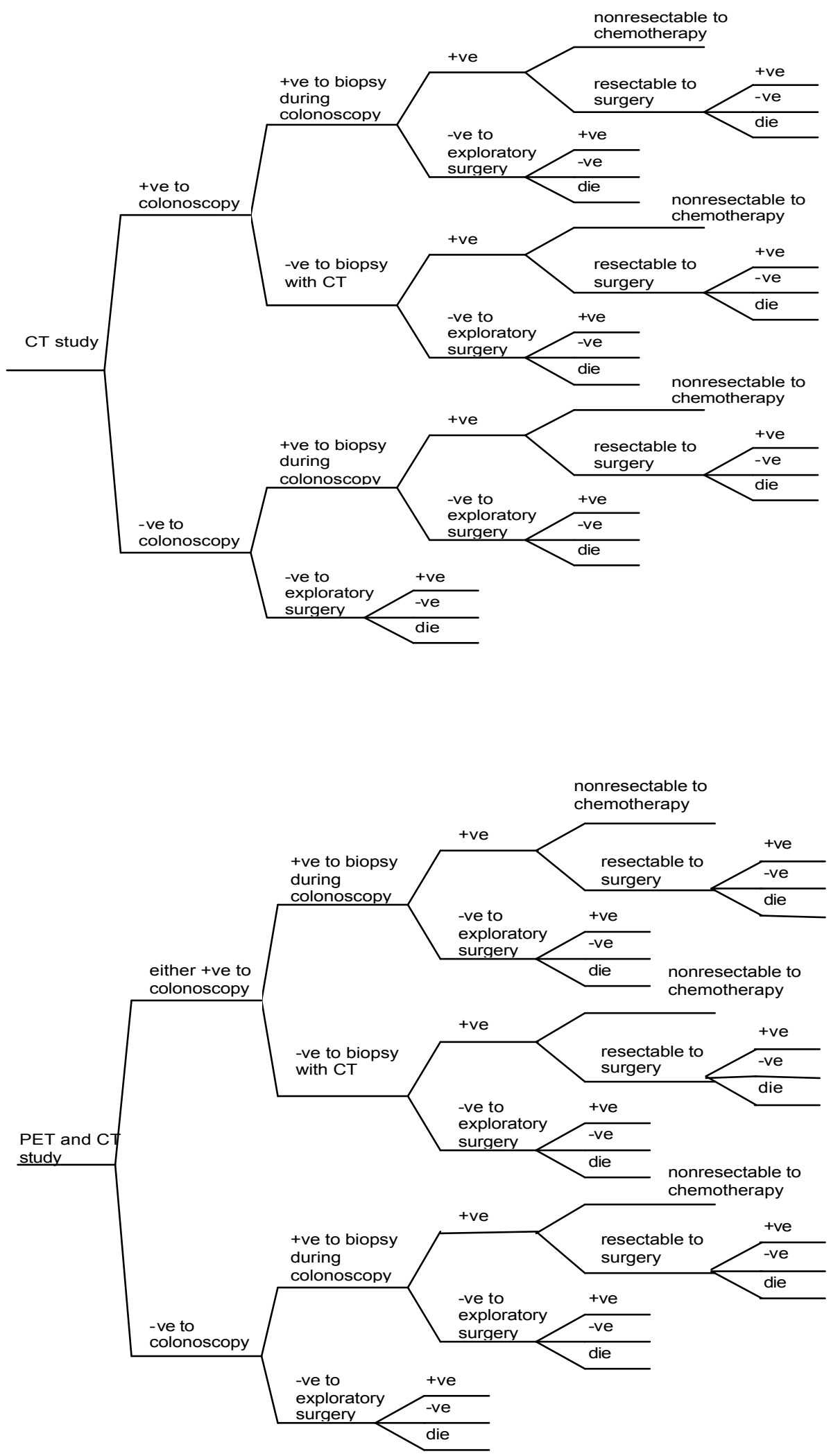

Figure 2- Decision tree for both PET and CT strategies. The outcomes of each test follow the test intersection, and each outcome is assigned a probability of occurring given the sensitivity and specificity of the test for that given block(33). The "+ve" in a particular test in the decision trees indicates that the patient has tested positive for disease. (5) 
where other tests failed to detect its existence. The combined alterations in surgical management for 10 studies where the detection of extensive metastases excluded the possibility of surgery resulted in a combined $28.7 \%$ of surgical candidates that were not eligible for surgery because of extensive metastases. These patients were subjected to unnecessary surgery (with an associated mortality, morbidity, and cost), whereas different treatment options would have been offered if better staging was available.

\section{Mortality data}

The associated risk of the various procedures are included in the decision tree model because they affect the life expectancy outcome of the patient. The mortality associated with CT is primarily attributable to the intravenous administration of contrast material, reported to be $0.0025 \%$ ( 1 in 40000 ) (38), and was chosen as a baseline mortality for this study $(39,40)$. No adverse reactions or complications due to the administration of FDG have been reported to date $(39,40)$.

The risk of mortality associated with the surgical resection of colon or rectum has been reported in several studies (41-48). There is wide variation in the report of several smaller studies; one large study from Australia (48) reported a perioperative mortality rate of $6.5 \%$, which was used for this study.

The reported complication rate of colonoscopy with biopsy is $0.2 \%$ (mainly due to perforation of the bowel), resulting in an approximate $0.005 \%$ mortality rate (49). Liver biopsy is also performed to confirm the presence of metastases, and the mortality from various large combined series is approximately $0.01 \%$ (50). Approximately $84 \%$ of recurrences include the colon or rectum, and approximately $12 \%$ of all recurrences metastasize only to the liver $(11,12)$. In our practice, all suspected colorectal recurrences would be biopsied, as well as all isolated suspected liver metastases. Therefore, this study used a weighted average mortality for biopsy of $0.84(0.005 \%)+0.12(0.01 \%)$, or $0.0054 \%$.

\section{Life expectancy}

The life expectancy of an average 65 year old Canadian is 18.3 years. The 5 year survival rate of people with recurrent colorectal cancer was recently reported to be $19.2 \%$ (a weighted average based on stage of disease) in a meta-analysis of several follow-up studies (51). Using the DEALE method for determining the 5 year survival rates of disease $(52,53)$, the life expectancy calculated for all patients with unstaged recurrent colorectal cancer is 2.6 years. The mean Survival of someone with untreated extensive colorectal metastasis is 13.1 months, whereas the mean survival of those treated with chemotherapy is 16.3 months (30).

\section{Costs}

Our current fee schedules and cost accounting systems along with the medical literature were surveyed to obtain the most recent Canadian values for all procedure costs and outcomes (Table 1). Year 2000 Canadian dollars was used as the currency, correcting for inflation using the Canadian Consumer Price Index (54). Costs outside the time horizon of the study, costs to society such as lost productivity, and indirect costs to quality of life were not used.

In this study, the cost of capital equipment is discounted over the expected lifetime of the equipment using a standard annuity formula, amortized over the equipment lifetime at an assumed interest rate of $6 \%$. Estimated equipment costs are outlined in Table 2. The estimated equipment lifetime for a positron tomograph is 5 years, and it is 10 years for a cyclotron installation (23).

For both a PET camera and a cyclotron, the estimated yearly operating cost is $\$ 1625 \mathrm{~K}$. Assuming that each PET installation operated at full potential on a 1 shift per day basis ( 7 patients per shift), there would be a yearly capacity for 1750 cases. The total cost per case would be $\$ 1625 \mathrm{~K} / 1750$ cases $=\$ 929 /$ case. Allowing for a physician remuneration of $\$ 100$ per case (an estimate based on other modalities), the total cost per case is estimated to be $\$ 1029$. Capital acquisition, depreciation, and annual operating estimates were not included for CT, because one CT study is performed per person in each strategy, and these costs cancel out when the two management strategies are compared. Overhead costs were not included in this analysis.

The cost of surgery for the resection of recurrent disease is calculated as an aggregate of bed costs and professional charges (Table 3). Those patients who undergo hepatic resection usually stay in hospital for 2 weeks, 5 days of which are spent in ICU. Those who undergo colorectal resection usually spend 1 to 2 weeks in a ward bed. Up to $35 \%$ of patients have resectable liver metastases. An average total cost for resection was estimated to be $\$ 16,479.34$. The cost of a thorax, abdomen and pelvic CT exam was estimated to be $\$ 200$ (55) plus $\$ 262$ professional costs. Professional costs for CT-guided biopsy are $\$ 118$, and $\$ 168$ for colonoscopy.

Estimates of the cost of chemotherapy for colorectal cancer were not available, although estimates of chemotherapy for lung cancer are known (56) and were used to roughly estimate the costs of chemotherapy to be $\$ 10,000$.

\section{Analysis}

Expected costs and outcomes were calculated for each of the decision models using a standard decision analysis software package (57). The probability of 
Table 2. PET Camera Capital and Operating Cost Estimates

\begin{tabular}{|c|c|c|c|}
\hline \multicolumn{2}{|l|}{ Capital Costs } & \multicolumn{2}{|l|}{ Operating Costs } \\
\hline $\begin{array}{l}\text { Conventional } \\
\text { Positron } \\
\text { Tomograph }\end{array}$ & $\$ 2500000$ & $\begin{array}{l}\text { Salaries for } 2 \\
\text { camera technologists }\end{array}$ & $\$ 93000$ \\
\hline \multirow[t]{7}{*}{ Cyclotron } & $\$ 2400000$ & $\begin{array}{l}\text { Part time for a } \\
\text { supporting scientist }\end{array}$ & $\$ 28000$ \\
\hline & & Camera supplies & $\$ 100000$ \\
\hline & & $\begin{array}{l}\text { Cyclotron salaries } \\
\text { for chemist, operator } \\
\text { and radiopharmacist }\end{array}$ & $\$ 175000$ \\
\hline & & Cyclotron supplies & $\$ 20000$ \\
\hline & & Cyclotron utilities & $\$ 15000$ \\
\hline & & 18F targets & $\$ 50000$ \\
\hline & & $\begin{array}{l}\text { Cyclotron } \\
\text { maintenance }\end{array}$ & $\$ 225000$ \\
\hline
\end{tabular}

Table 3. Cost structure for surgical resection..

* represents hospital costs that were assumed to have been combined into bed cost per day.

\begin{tabular}{|c|c|c|}
\hline \multicolumn{3}{|l|}{ Surgery } \\
\hline \multicolumn{3}{|l|}{ Preoperative testing } \\
\hline EKG & $\$ 63.25$ & \\
\hline Chest $\mathrm{X}$ ray & $\$ 10.55$ & \\
\hline Blood tests & $*$ & \\
\hline \multicolumn{3}{|l|}{ Preoperative consult } \\
\hline Surgeon & $\$ 49.92$ & \\
\hline \multicolumn{3}{|l|}{ Preadministrative clinic } \\
\hline Nurse & $*$ & \\
\hline Medical problems -> specialist & Variable & \\
\hline Anesthesiologist consult & $\$ 33.50$ & \\
\hline \multicolumn{3}{|l|}{ Operating room } \\
\hline Equipment & * & \\
\hline Facilities & $*$ & \\
\hline Anesthesiologist fees & $\$ 149.52$ & \\
\hline Surgeon fees & $\$ 534.65$ & \\
\hline & $\$ 232.87$ & \\
\hline Nurse assistant fees & * & \\
\hline Surgical assistant fees & $\$ 32.04$ & \\
\hline Additional person & $\$ 32.04$ & \\
\hline Intraoperative ultrasound to assess liver & $\$ 17.69$ & \\
\hline Recovery room nurse & $*$ & \\
\hline Recovery room costs & $*$ & \\
\hline Total & $\$ 1,156.03$ & \\
\hline ICU & Ward & \\
\hline $\begin{array}{l}\text { Bed cost per day } \\
\text { ICU Specialist costs } \\
\text { First day }\end{array}$ & $\begin{array}{l}\text { Bed cost } \\
\text { per day }\end{array}$ & $\$ 840.00$ \\
\hline
\end{tabular}

outcome at each decision step was derived from assigned prevalences, sensitivities, and specificities (33). Total expected costs and outcomes were calculated given the probability of outcome at each node (33). Sensitivity analysis was performed on all key variables to analyze sensitivity of results to inaccuracies of parameter estimates.

\section{RESULTS}

Given our theoretical sample of 1000 patients presenting for diagnostic evaluation and treatment, 580 surgeries would be performed with the CT model and 455 surgeries would be performed with the PET model. 125 people would avoid unnecessary surgery with the PET model compared to the CT model, due to a reduction in false positives from inaccurate staging. These patients would be sent directly to alternate forms of therapy and/or palliation without the additional risks of surgery. This large difference is due to the more accurate staging with the PET modality, but it significantly depends on the accuracy of biopsy in this model, conservatively assumed to be $100 \%$. This difference also depends on the mutual exclusivity of the two diagnostic imaging modalities, which will never be the case in practice.

The expected cost of the CT alone strategy was $\$ 9,523$ per person, and the expected cost of the PET strategy was $\$ 7,765$ per person, translating to an expected savings of $\$ 1,758$ per person using the PET strategy. This savings is associated with an increase in life expectancy ( 3.8 days). These results are due to the improved staging of recurrent colorectal cancer prior to surgery; patients with inoperable metastatic disease are directed away from surgery, a procedure associated with a high cost and mortality rate. Since the change in life expectancy is 3.8 days (in favour of the PET model), cost effectiveness calculations were not performed due to clinical insignificance. However, this change in life expectancy also demonstrates that the addition of PET into the decision model is not detrimental to the health of the patient.

Sensitivity analysis was performed on key parameters (such as the cost of an FDG-PET study or the specificity of a CT study) to determine the sensitivity of the cost savings and life expectancy to variation of these inputs (Table 4). For example, the expected cost per person is lower using the PET strategy unless the cost of a PET study increases beyond $\$ 2,787$. Table 4 shows the limits at which the PET strategy has an expected cost per person less than the CT strategy, and Table 10 shows the limits at which the PET strategy demonstrates a better life expectancy per person than the CT strategy.

The sensitivity analysis shows that if the sensitivity and specificity of PET is reduced to $74.8 \%$ and $67.3 \%$ respectively, the CT only strategy has a lower expected cost. This is because the accuracy of PET has been reduced to the accuracy of $\mathrm{CT}$, making the accuracy of staging for both models similar. The percentage of people that avoided surgery was also subjected to sensitivity analysis and it was determined that the PET strategy has a lower expected cost if the percentage of 
Table 4. Sensitivity analysis for variables of interest used in the decision model. The variables of interest were varied until the expected cost/life expectancy of the CT strategy became less than the expected cost/life expectancy of the PET strategy. The "any" signifies that for any value of the given variable, the PET strategy is more cost effective than the CT strategy.

\begin{tabular}{llll}
\hline Variable of Interest & $\begin{array}{l}\text { Cost } \\
\text { Effectiveness }\end{array}$ & $\begin{array}{l}\text { Life } \\
\text { Expectancy }\end{array}$ & $\begin{array}{l}\text { B a s e I i n e } \\
\text { Value }\end{array}$ \\
\hline Disease prevalence & $>22.4 \%$ & $>17.5 \%$ & $85 \%$ \\
CT Cost & any & & $\$ 462$ \\
PET Cost & $<\$ 2787$ & & $\$ 1029$ \\
Surgery Cost & $>\$ 2922$ & & $\$ 16479$ \\
Biopsy Cost & any & & $\$ 118$ \\
Chemotherapy Cost & $<\$ 100000$ & & $\$ 10000$ \\
CT sensitivity & $<87.3 \%$ & $<91.8 \%$ & $76.2 \%$ \\
CT specificity & any & any & $69.4 \%$ \\
PET sensitivity & $>73.8 \%$ & $>44.3 \%$ & $92.9 \%$ \\
PET specificity & $>65.3 \%$ & $>51.2 \%$ & $93.4 \%$ \\
Avoidance of surgery & $>3.2 \%$ & $>11.3 \%$ & $28.7 \%$ \\
Non-resectable & $<95.0 \%$ & $<71.6 \%$ & $54-71 \%$ \\
& & & $(13-16)$ \\
\hline
\end{tabular}

people that avoid surgery is greater than $3.2 \%$ of the people that are considered for curative surgery, which is much less than the value that was determined through the meta-analysis $(28.7 \%)$. As well, for the PET strategy to be more cost effective than the CT strategy, less than $95.0 \%$ of patients should have non-resectable disease.

If the cost of surgery was reduced to less than $\$ 2922$, the CT strategy would have a lower expected cost. Since the estimated cost of surgery is $\$ 16,479$, the sensitivity for variations in this cost is low. However, if the screening procedures were not sufficiently accurate and they reduced the prevalence of the disease in the population of people presenting for diagnostic test at this level to less than $22.4 \%$ (our study estimate is $85 \%$ ), the CT strategy would become more cost effective in terms of expected cost per patient. The cost of chemotherapy was varied between $0 \$$ and $\$ 100 \mathrm{~K}$ and the PET strategy was economical for this entire range.

\section{DISCUSSION}

The cost of medical care in Canada continues to rise, and now stands at $\$ 100$ billion per year, approximately $9.3 \%$ of the gross domestic product(58). Due to the high cost of health care and the expectations of the Canadian people for a quality health care system with the best available diagnostic tools, clinical decisionmaking should also consider the cost of these decisions. It is desirable to find evidence-based clinical decisionmaking strategies where both a clinical and economic benefit coexist. Using a theoretical sample of 1000 patients and a decision tree analysis, we found that $\mathrm{CT}+\mathrm{PET}$ were a cost-effective approach to determining the management of recurrent colorectal cancer. The additional PET study cost is more than compensated for by the savings realized from avoided surgeries. Over a range of values for the procedural parameters, the PET+CT strategy is shown to be more cost effective than the CT only strategy. There is a cost benefit of approximately $\$ 1,758$ per person without a reduction in life expectancy.

Patients may benefit in several ways from the additional accuracy of staging techniques. Patients are fearful of recurrence (having been through the treatment of cancer at least once already) and accurate detection and staging contribute to their peace of mind. As well, morbidity and mortality are reduced through the avoidance of inappropriate surgery.

This study did not include the use of PET to stage primary colorectal cancer on initial presentation, although successful clinical studies have been performed to determine the usefulness PET in staging primary colorectal cancers (59) and for the evaluation of metastases to the liver $(4,6)$.

A key assumption of this model is that this is a theoretical sample of 1000 patients who are at an average age for recurrent colorectal cancer. The accuracy of CT and PET may depend on the age of the population under study. This model was also constructed using our local practices which may or may not be similar to other practices elsewhere.

Another key assumption was that a "critical mass" of patients is needed for full utilization of a PET camera and cyclotron. Our calculations were based on full utilization; however, some centers in Canada do not have sufficient patient demand in terms of recurrent colorectal cancer to run a single shift daily for five days a week. Regions with underutilization would incur a higher cost than those without due to equivalent capital and yearly operating costs, but lower savings from fewer surgeries avoided. More study is required to determine regional options for centers with smaller catchments.

Selection of clinical studies for the meta analysis did not exclude studies that did not blind their results between $\mathrm{CT}$ and $\operatorname{PET}(39,40)$. In these cases, many patients are selected for PET imaging because of positive CT findings, thus introducing a case-selection bias resulting in an over-representation of positive CT findings (both false and true), with a concomitant overestimation of CT sensitivity and underestimation of specificity. Therefore, the CT and PET tests are not conditionally independent and some results do depend on diagnostic sequence. This does not, however, invalidate the meta analysis because the purpose is to determine the impact of adding a new modality to the patient's diagnostic algorithm, and the final test does 
demonstrate accuracy (2). The clinical question for several studies centered on the detection of liver metastases, and for other studies the clinical question measured the detection of the recurrence of localized disease. Since both types of information are used to stage the disease, and since the staging of disease directs the management of the disease, both of these types of studies were included. It might be argued that the combination will increase the total accuracy because results from one modality may direct another.

Several assumptions were made to facilitate procedural modeling. The assumption that the biopsy is $100 \%$ accurate is not valid - biopsy may miss some lesions due to sampling error. Total costs, including clinician costs, blood tests, and other screening costs, were not included in this analysis but, similar to the minimal effect of CT cost variability on the expected cost savings, additional matched costs to both strategies may cancel out. At present, the use of PET technology has some drawbacks including the reliability of diagnosing tumors that are less than $1 \mathrm{~cm}^{3}$. The metaanalysis is not as strict as it could be. The inclusion of several studies with clinical designs that are not $100 \%$ compatible is not optimal, but it does provide a more generalized approach for determining the overall accuracy of these diagnostic methods. At the present time, only one prospective study (2) has been published.

Overhead costs, palliative care costs and costs associated with quality of life were not included in this model. The overhead costs associated with operating a new PET center are unknown. It is assumed that these costs would be taken over by the imaging department and that shared costing within the department would reduce the costs incurred by each camera. The cost of chemotherapy was also not known and had to be estimated.

People who require palliation and who are sent to inappropriate resection surgery due to incorrect staging eventually require palliative care. As well, people that are falsely negative for recurrence yet have nonresectable disease may eventually present for palliation. Therefore, we assumed that those people who may require palliation will eventually receive palliation and so these costs do not change with the addition of a new diagnostic modality. This assumption may not be accurate because false negatives may present later for palliation (at a reduced total cost of palliation). False negative are reduced with the addition of PET. Therefore, a higher palliation cost may be realized for the addition of a more accurate diagnostic tool.

Quality of life can be represented in terms of actual costs (QALY). These costs were not included in this study. However, reducing the number of surgeries in people that do not require surgery would theoretically increase the quality of life in people that are determined to make the most out of life while they can.

The theoretical population sample may not reflect the actual population that presents for diagnosis. A sample of an average age of people presenting for diagnosis (a 65 year old) may not be representative of a regional population. As well, the accuracy of diagnosis of PET and CT could change with different population age (since the index of suspicion for recurrence may change). However, the change in life expectancy would be similar for any age since the change is strictly due to the reduction in the number of deaths due to surgery. A study based on real patient data would provide a more accurate representation.

\section{CONCLUSIONS}

Colorectal cancer is an important cause of morbidity and mortality in Canada; it is the 3rd most common cancer and the $3 \mathrm{rd}$ most common cause of cancer death. 17000 new cases of colorectal cancer are expected this year and the lifetime risk of colorectal cancer is $6 \%$. This study has described the use of PET technology for the staging of recurrent colorectal carcinoma, and may benefit patients in terms of a minor increase in life expectancy of 3.8 days, but it could also benefit the Canadian people in terms of reduced health care costs. This was shown to be true even for a wide variation in approximated variables used by this analysis. This study indicates that PET may be used economically in Canada in certain clinical situations.

\section{REFERENCE}

1. National Cancer Institute of Canada. Canadian Cancer Statistics 2000, Toronto, Canada, 2000. 2001.

2. Valk PE, Abella-Columna E, Haseman MK, Pounds TR, Tesar $\mathrm{RD}$, Myers RW et al. Whole-body PET imaging with $\left[{ }^{18}\right.$ F]fluorodeoxyglucose in management of recurrent colorectal cancer. Arch Surg 1999; 134(5):503-511.

3. Schiepers C, Penninckx F, De Vadder N, Merckx E, Mortelmans $\mathrm{L}$, Bormans $\mathrm{G}$ et al. Contribution of PET in the diagnosis of recurrent colorectal cancer: comparison with conventional imaging. Eur J Surg Oncol 1995; 21(5):517-522.

4. Vitola JV, Delbeke D, Sandler MP, Campbell MG, Powers TA, Wright JK et al. Positron emission tomography to stage suspected metastatic colorectal carcinoma to the liver. Am J Surg 1996; 171(1):21-26.

5. Delbeke D, Vitola JV, Sandler MP, Arildsen RC, Powers TA, Wright JK, Jr. et al. Staging recurrent metastatic colorectal carcinoma with PET. J Nucl Med 1997; 38(8):1196-1201.

6. Boykin KN, Zibari GB, Lilien DL, McMillan RW, Aultman DF, McDonald JC. The use of FDG-positron emission tomography for the evaluation of colorectal metastases of the liver. Am Surg 1999; 65(12):1183-1185.

7. Fong Y, Saldinger PF, Akhurst T, Macapinlac H, Yeung H, Finn $\mathrm{RD}$ et al. Utility of 18F-FDG positron emission tomography scanning on selection of patients for resection of hepatic colorectal metastases. Am J Surg 1999; 178(4):282-287.

8. Flanagan FL, Dehdashti F, Ogunbiyi OA, Kodner IJ, Siegel BA. Utility of FDG-PET for investigating unexplained plasma CEA 
elevation in patients with colorectal cancer. Ann Surg 1998; 227(3):319-323.

9. Hoh CK, Schiepers C, Seltzer MA, Gambhir SS, Silverman DH, Czernin $\mathrm{J}$ et al. PET in oncology: will it replace the other modalities? Semin Nucl Med 1997; 27(2):94-106.

10. Conti PS, Lilien DL, Hawley K, Keppler J, Grafton ST, Bading JR. PET and $\left[{ }^{18} \mathrm{~F}\right]-\mathrm{FDG}$ in oncology: a clinical update. Nucl Med Biol 1996; 23(6):717-735.

11. Desch CE, Benson AB, III, Smith TJ, Flynn PJ, Krause C, Loprinzi CL et al. Recommended colorectal cancer surveillance guidelines by the American Society of Clinical Oncology. J Clin Oncol 1999; 17(4):1312.

12. August DA, Ottow RT, Sugarbaker PH. Clinical perspective of human colorectal cancer metastasis. Cancer Metastasis Rev 1984; 3(4):303-324.

13. Grage TB, Vassilopoulos PP, Shingleton WW, Jubert AV, Elias EG, Aust JB et al. Results of a prospective randomized study of hepatic artery infusion with 5-fluorouracil versus intravenous 5fluorouracil in patients with hepatic metastases from colorectal cancer: A Central Oncology Group study. Surgery 1979; 86(4):550-555.

14. Macdonald JS, Kisner DF, Smythe T, Woolley PV, Smith L, Jr., Schein PS. 5-Fluorouracil (5-FU), methyl-CCNU, and vincristine in the treatment of advanced colorectal cancer: phase II study utilizing weekly 5-FU. Cancer Treat Rep 1976; 60(11):1597-1600.

15. Buroker T, Kim PN, Groppe C, McCracken J, O'Bryan R, Panettiere $\mathrm{F}$ et al. 5FU infusion with mitomycin-C versus $5 \mathrm{FU}$ infusion with methyl-CCNU in the treatment of advanced colon cancer: a Southwest Oncology Group Study. Cancer 1978; 42(3):1228-1233.

16. Kemeny N, Younes A, Seiter K, Kelsen D, Sammarco P, Adams $\mathrm{L}$ et al. Interferon alpha-2a and 5-fluorouracil for advanced colorectal carcinoma. Assessment of activity and toxicity. Cancer 1990; 66(12):2470-2475.

17. Cohen AM, Minsky BD, Schilsky RL.In: De Vita VT,Jr. Hellmann S, Rosenberg SA (eds). Cancer: principles and practice of oncology, 4th ed. Lippincott, Philadelphia, p929.

18. Taylor I. Liver metastases from colorectal cancer: lessons from past and present clinical studies. Br J Surg 1996; 83(4):456-460.

19. Foster JH, Lundy J. Liver Metastases. Curr Probl Surg 1981; 18(3):157-202.

20. Fong Y, Salo J. Surgical therapy of hepatic colorectal metastasis. Semin Oncol 1999; 26(5):514-523.

21. Johannesson M. On the estimation of cost-effectiveness ratios. Health Policy 1995; 31(3):225-229.

22. Dsetlein M, Sheidhauer K, Lautenbach K, Schicha H. Quality criteria for cost-benefit analysis in oncological nuclear medicine. Zeitschrift fur Arzlich Fortbildung und Qualitatssichanung 93[1], 49-55. 2001.

23. Beanlands R, Chamberlain M, Cripps C, et al. Position paper on the future of positron emission tomography in Ontario. Council of Medical Imaging, Oakville, Ontario . 2001. 1999.

24. Institute for Clinical PET. Clinical application and economic implications of PET in the assessment of colorectal cancer recurrence: A retrospective study. ICP International Conference 2001.

25. Chiappa A, Zbar AP, Biella F, Staudacher C. Survival after repeat hepatic resection for recurrent colorectal metastases. Hepatogastroenterology 1999; 46(26):1065-1070.

26. Law WL, Chu KW, Ho JW, Tung HM, Law SY, Chu KM. Selfexpanding metallic stent in the treatment of colonic obstruction caused by advanced malignancies. Dis Colon Rectum 2000; 43(11):1522-1527.

27. Cheung PC, Mackillop WJ, Dixon P, Brundage MD, Youssef YM, Zhou S. Involved-field radiotherapy alone for early-stage non-small-cell lung cancer. Int J Radiat Oncol Biol Phys 2000; 48(3):703-710.

28. Hoffman PC, Mauer AM, Vokes EE. Lung cancer. Lancet 2000; 355(9202):479-485.

29. Knott-Craig CJ, Howell CE, Parsons BD, Paulsen SM, Brown $\mathrm{BR}$, Elkins RC. Improved results in the management of surgical candidates with lung cancer. Ann Thorac Surg 1997; 63(5):1405-1409.

30. Durand-Zaleski I, Roche B, Buyse M, Carlson R, O'Connell MJ, Rougier $\mathrm{P}$ et al. Economic implications of hepatic arterial infusion chemotherapy in treatment of nonresectable colorectal liver metastases. Meta-Analysis Group in Cancer. J Natl Cancer Inst 1997; 89(11):790-795.

31. Oxman AD, Cook DJ, Guyatt GH. Users' guides to the medical literature. VI. How to use an overview. Evidence-Based Medicine Working Group. JAMA 1994; 272(17):1367-1371.

32. Gambhir SS. Decision analysis in nuclear medicine. J Nucl Med 1999; 40(9):1570-1581.

33. Sox HC. Medical decision making. Butterworths . 2001. Boston.

34. Akhurst T, Larson SM. Positron emission tomography imaging of colorectal cancer. Semin Oncol 1999; 26(5):577-583.

35. Beets G, Penninckx F, Schiepers C, Filez L, Mortelmans L, Kerremans $\mathrm{R}$ et al. Clinical value of whole-body positron emission tomography with $\left[{ }^{18} \mathrm{~F}\right]$ fluorodeoxyglucose in recurrent colorectal cancer. Br J Surg 1994; 81(11):1666-1670.

36. Lai DT, Fulham M, Stephen MS, Chu KM, Solomon M, Thompson JF et al. The role of whole-body positron emission tomography with $\left[{ }^{18}\right.$ F]fluorodeoxyglucose in identifying operable colorectal cancer metastases to the liver. Arch Surg 1996; 131(7):703-707.

37. Imdahl A, Reinhardt MJ, Nitzsche EU, Mix M, Dingeldey A, Einert A et al. Impact of 18F-FDG-positron emission tomography for decision making in colorectal cancer recurrences. Langenbecks Arch Surg 2000; 385(2):129-134.

38. Hartman GW, Hattery RR, Witten DM, Williamson B, Jr. Mortality during excretory urography: Mayo Clinic experience. AJR Am J Roentgenol 1982; 139(5):919-922.

39. Gambhir SS, Hoh CK, Phelps ME, Madar I, Maddahi J. Decision tree sensitivity analysis for cost-effectiveness of FDGPET in the staging and management of non-small-cell lung carcinoma. J Nucl Med 1996; 37(9):1428-1436.

40. Kosuda S, Ichihara K, Watanabe M, Kobayashi H, Kusano S. Decision-tree sensitivity analysis for cost-effectiveness of chest 2- fluoro-2-D-[( $\left.{ }^{18}\right)$ F]fluorodeoxyglucose positron emission tomography in patients with pulmonary nodules (non-small cell lung carcinoma) in Japan. Chest 2000; 117(2):346-353.

41. Bohm B, Grundel K, Neudecker J, Schwenk W. [Can colorectal carcinomas be resected laparoscopically? Technically possible, long-term outcome is still uncertain]. MMW Fortschr Med 2000; 142(8):30-32.

42. Baccari P, Di Palo S, Redaelli A, Carlucci M, Staudacher C. [Laparoscopic versus conventional surgery in the treatment of colorectal diseases]. Chir Ital 2000; 52(1):17-27.

43. Bolton JS, Fuhrman GM. Survival after resection of multiple bilobar hepatic metastases from colorectal carcinoma. Ann Surg 2000; 231(5):743-751.

44. Imamura H, Kawasaki S, Miyagawa S, Ikegami T, Kitamura H, Shimada R. Aggressive surgical approach to recurrent tumors after hepatectomy for metastatic spread of colorectal cancer to the liver. Surgery 2000; 127(5):528-535.

45. Schiedeck TH, Schwandner O, Baca I, Baehrlehner E, Konradt J, Kockerling F et al. Laparoscopic surgery for the cure of colorectal cancer: results of a German five-center study. Dis Colon Rectum 2000; 43(1):1-8.

46. Rosen SA, Buell JF, Yoshida A, Kazsuba S, Hurst R, Michelassi $\mathrm{F}$ et al. Initial presentation with stage IV colorectal 
cancer: how aggressive should we be? Arch Surg 2000; 135(5):530-534.

47. Fernandez Merino FJ, Vicente LE, Nuno GJ, Zarzosa G, Barrasa SA, Meneu JC. Resection of colorectal liver metastases: analysis of risk factors. Rev Esp Enferm Dig 2000; 92(2):97104.

48. Ansari MZ, Collopy BT, Hart WG, Carson NJ, Chandraraj EJ. In-hospital mortality and associated complications after bowel surgery in Victorian public hospitals. Aust N Z J Surg 2000; 70(1):6-10.

49. Hart R, Classen M. Complications of diagnostic gastrointestinal endoscopy. Endoscopy 1990; 22(5):229-233.

50. Sherlock S DJ. Diseases of the liver and biliary system, 10th ed. London: Blackwell Science . 2001

51. Kievit J. Colorectal cancer follow-up: a reassessment of empirical evidence on effectiveness. Eur J Surg Oncol 2000; 26(4):322-328.

52. Beck JR, Kassirer JP, Pauker SG. A convenient approximation of life expectancy (the "DEALE"). I. Validation of the method. Am J Med 1982; 73(6):883-888.

53. Beck JR, Pauker SG, Gottlieb JE, Klein K, Kassirer JP. A convenient approximation of life expectancy (the "DEALE"). II.
Use in medical decision-making. Am J Med 1982; 73(6):889897.

54. Evans WK, Will BP, Berthelot JM, Wolfson MC. The economics of lung cancer management in Canada. Lung Cancer 1996; 14(1):19-29.

55. Investigation for mediastinal disease in patients with apparently operable lung cancer. Canadian Lung Oncology Group. Ann Thorac Surg 1995; 60(5):1382-1389.

56. Coy P, Schaafsma J, Schofield JA. The cost-effectiveness and cost-utility of high-dose palliative radiotherapy for advanced non-small-cell lung cancer. Int J Radiat Oncol Biol Phys 2000; 48(4):1025-1033.

57. Gambhir SS, Gupta P, Shepherd JE, Allen MA, Hoh C, Maddahi $\mathrm{J}$ et al. MD@: a physician-friendly decision analysis tool. MD Comput 1998; 15(1):40-48.

58. Canadian Institute for Health Information. Health Care in Canada. ISBN: 1-55392-018-X. 9-5-2002.

59. Abdel-Nabi H, Doerr RJ, Lamonica DM, Cronin VR, Galantowicz PJ, Carbone GM et al. Staging of primary colorectal carcinomas with fluorine-18 fluorodeoxyglucose whole-body PET: correlation with histopathologic and CT findings. Radiology 1998; 206(3):755-760.

Scott Sloka is the first year neurology resident at MUN. He holds a BASc in Electrical Engineering and a PhD in Image Processing from theUniversity of Waterloo and an MD from Memorial University of Newfoundland. His research interests include image understanding, pattern recognition, autoimmunity and neuroepidemiology.

Peter Hollett is the chief of Nuclear Medicine at the Health Care Corporation for St. John's. His research interests include nuclear cardiology, respiratory disease and endocrine disorders.

Maria Mathews is an Assistant Professor of Health Policy/Health Care Delivery in the Division of Community Health, Faculty of Medicine, Memorial University of Newfoundland. She has a PhD in Health Policy, Management, and Evaluation from the University of Toronto and a Masters in Health Services. Administration from the University of Alberta. Her research interests include access issues in cancer care and primary care, and improving evidence based practice in health services management. 